\title{
The Hepatic Flora and Floristic Affinity of Hepatics Around Takakia Lake, Queen Charlotte Islands, British Columbia
}

\author{
WON SHIC Hong \\ Department of Biology, University of Great Falls, Great Falls, Montana 59405-4934 USA.
}

Hong, Won Shic. 2007. The hepatic flora and floristic affinity of hepatics around Takakia Lake, Queen Charlotte Islands, British Columbia. Canadian Field-Naturalist 121(1): 24-28.

The known hepatic flora of the Takakia Lake area consists of 66 species, 2 subspecies, and 2 varieties, in 30 genera and 18 families. Thirty-seven taxa (51.8\%) of the total 70 taxa present are boreal in distribution. Seven taxa (10.1\%) are western North American and Amphi-Pacific elements. This clearly demonstrates that the greatest diversity of western North American hepatics occurs between $45^{\circ}-55^{\circ} \mathrm{N}$ and between $120^{\circ}-135^{\circ} \mathrm{W}$ which includes the lake (Hong 1988). Other distribution patterns include a taxon which is a North American boreal endemic and one which is a North American temperate endemic; two are cosmopolitan and disjunct montane; three are circumtemperate and circum-montane; six are temperate disjunct; eight are arctic and alpine; fourteen are boreal disjunct and twenty-three are circumboreal.

Key Words: Hepatics, Takakia Lake, Queen Charlotte Islands, British Columbia.

Takakia Lake is a high-elevation lake located on the northwestern part of Moresby Island, one of 150 islands that comprise the Queen Charlotte Islands $\left(31^{\circ} 54^{\prime}-\right.$ $54^{\circ} 13^{\prime} \mathrm{N}$ to $\left.130^{\circ} 58^{\prime}-133^{\circ} 06^{\prime} \mathrm{W}\right)$. The lake $\left(52^{\circ} 55^{\prime} \mathrm{N}\right.$ and $132^{\circ} 03^{\prime} \mathrm{W}$ ) is situated at almost $650 \mathrm{~m}$ above sea level just at the tree line and measures $1.25 \mathrm{~km}$ in length and $0.75 \mathrm{~km}$ in width.

Before the discovery of the rare bryophyte Takakia lepidozioides (on soil, partly covering rocks) by Persson in 1958, the lake was unnamed (Figure 1).

The first report of Takakia lepidozioides was made by Hattori and Inoue (1958) using the specimen collected by Takaki in 1951 at $2400 \mathrm{~m}$ altitude on Mt. Shirouma, Japanese Alps, middle Japan. They described this species as a member of hepatics and placed it under the new order Takakiales, and the new family, Takakiaceae, based on sterile materials. Later the species was found in Borneo (Hattori 1963) and another species of Takakia, T. ceratophylla, was found in the Himalayas (Grolle and Long 2000).

For many years after the discovery of this species, many bryologists sought sporophytes of Takakia. Finally in 1990, Smith and Davidson (1990) reported sporophytes in the central Aleutian Islands and clarified the systematic position of Takakia as a moss with links to Andreaeopsida, previously suggested by Mizutani (1974) and Murray (1988).

The surrounding hills of Takakia Lake are mainly noncalcareous substrates which receive almost $5000 \mathrm{~mm}$ annual precipitation; they are dominated by Sitka Spruce (Picea sitchensis) and Western Hemlock (Tsuga heterophylla). There are many suitable moist areas that favor the growth of hepatics, especially alpine meadows that have developed on north-exposed slopes of the lowest part of the alpine region at the eastern end of the lake.

The most common herbs are Senecio triangularis, Mitella pentandra, Habenaria saccata, Vahlodea atrop- urpurea, Eriophorum angustifolium, Erigeron peregrinus, Veratrum eschscholtzii, Saxifraga punctata, Cardamine umbellata, Epilobium delicatum, Tiarella trifoliata, Dodecatheon jeffreyi, and Heracleum lanatum (Calder and Taylor 1968). Hepatics are abundant along a small stream running through the meadows.

In 1969, V. J. Krajina and his colleagues of Department of Botany, University of British Columbia, proposed that the provincial government preserve the lake as an ecological reserve, citing the need to protect representative ecosystems, rare genetic resources, and outstanding biological phenomena in a remote alpine setting. The proposal was considered by the government; however, it was never approved.

The lake flows into Moresby Lake, which feeds a turbine and supplies electric power to Moresby Island and the southern part of Graham Island. In 1997, Queen Charlotte Power Corporation from Vancouver, British Columbia, proposed the drilling of holes into Takakia Lake to supply water for more electric power, thus reducing the water level of the lake. Any such drawdown of the lake would destroy the sensitive habitat of most of its endangered or threatened species of plants, especially hepatics, mosses and lichens.

It is necessary to preserve the lake's constant water level to protect this unique representative ecosystem of an alpine lake, rare genetic resources, and outstanding biological phenomena in a remote, clear, and unpolluted lake. Hepatics especially are so sensitive to humidity that if water were drained from the lake during their vigorous growing season (summer), they would die or would disappear. Such phenomena have been clearly demonstrated by the cutting of old-growth forests around various lakes or along the stream banks resulting in reduced water availability.

Along the shore line of Takakia Lake, there are numerous rare species vulnerable to water level change, 


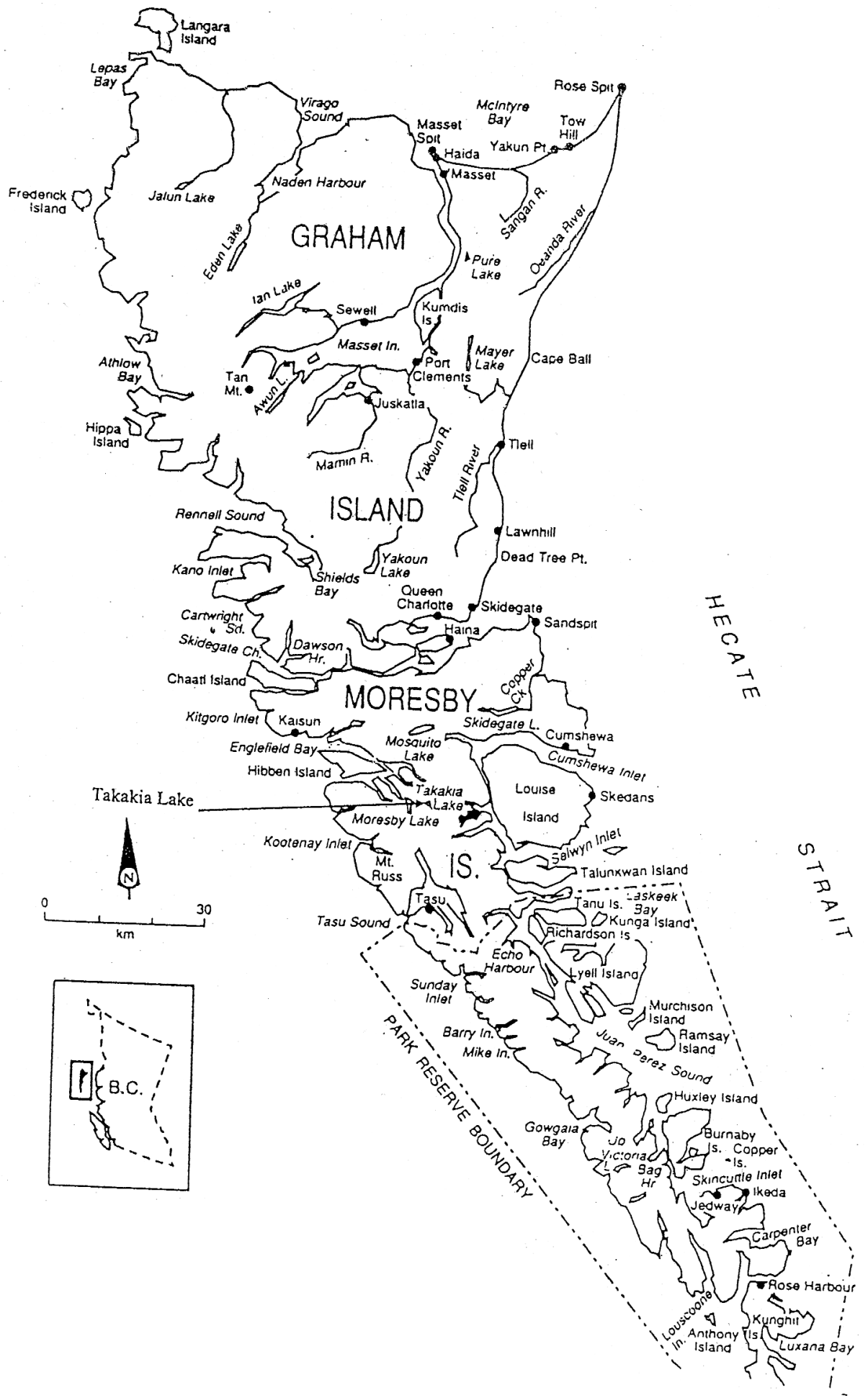

FIGURE 1. Takakia Lake in Queen Charlotte Islands (after Provisional Resource Description \& Analysis, South Moresby/ Gwaii Haanas National Park Reserve 1990) 
including Takakia lepidozioides (under Musci), and the following hepatics: Anastrophyllum assimile, Anthelia julacea, Diplophyllum imbricatum, D. plicatum, Gymnomitrion pacificum, Herbertus sakuraii, Hygrobiella laxifolia, Kurzia sylvatica, Lepidozia filamentosa, Marsupella alpina, M. boeckii, Pleurocladula albescens, and Pleurozia purpurea.

In order to secure luxurious growth and maintenance of its biodiversity of bryophytes through ample moisture, a constant water level should be maintained in Takakia Lake.

The author made collecting trips during the summers of 1999, 2000 and 2001. Voucher specimens have been deposited at the herbarium of the University of Great Falls, Montana (GFC), with available duplicates in the herbarium of University of Cincinnati (CINC). This report is based on author's collections, specimens borrowed from Chicago Natural History Museum (F), Swedish Museum of Natural History (S), and University of British Columbia (UBC) and literature reports from the following: Persson (1958); Miller (1968); Schofield (1968); Hong (1992, 1993). In general, nomenclature follows Stotler and Crandall-Stotler (1977) and Grolle and Long (2000). Only one representative specimen of each taxon is cited. Genera and species are listed alphabetically.

\section{Annotated Checklist of the Liverworts of Takakia Lake Area}

Anastrophyllum (Spruce) Steph.

assimile (Mitt.) Steph. - wet cliff crevices. (Persson 1958)

Anthelia (Dumort.) Dumort.

julacea (L.) Dumort. - wet rocks. 00-397.

juratzkana (Limpr.) Trevis - humus on rocks. 99-179.

Barbilophozia Loeske

floerkei (F. Weber \& D. Mohr) Loeske - shaded rocks. 00-400.

hatcheri (A. Evans) Loeske - partially shaded ledge. Persson s.n.(S).

kunzeana (Huebener) Müll. Frib. - moist ledge. Schofield $25158(\mathrm{~F})$.

lycopodioides (Wallr.) Loeske - shaded, moist ledge. Persson s.n. (S).

Bazzania Gray

pearsonii Steph. - rocks and soil. Schofield 25158 (UBC). (Schofield 1968).

tricrenata (Wahlenb.) Lindb. - bark, decayed wood, and soil. 99-256.

Blepharostoma (Dumort.) Dumort.

trichophyllum (L.) Dumort. subspecies trichophyllum shaded, moist soil, rocks and decayed wood. 99-180

Calypogeia Raddi

azurea Stotler \& Crotz. - shaded, decayed wood and moist soil. (Persson 1958).

integristipula Steph. - shaded, decayed wood and moist soil. 01-206.

neesiana (C. Massal. \& Carestia) Müll. Frib. - shaded, decayed wood and moist soil. 99-208.

Cephalozia (Dumort.) Dumort.

ambigua C. Massal. - shaded, decayed wood and moist soil. 015-216.

bicuspidata (L.) Dumort. - shaded, decayed wood 99-195. leucantha Spruce - shaded, decayed wood. 01-230.

lunulifolia (Dumort.) Dumort. - shaded decayed wood. wet rocks and stream banks. 99-180.

macounii (Austin) Austin - decayed wood and moist soil. 99-182.

Diplophyllum (Dumort.) Dumort.

albicans (L.) Dumort. - shaded, decayed wood, soil and rocks. 99-170.

imbricatum (M. A. Howe) Müll. Frib. - rocks. (Persson 1958; Hong 1993).

plicatum Lindb. - shaded, decayed wood and thin soil over wet rocks. (Persson 1958).

taxifolium (Wahlenb.) Dumort. - shaded ledge. 99-253.

Eremontus Lidnb. \& Kaalaas in Pearsson

myriocarpus (Carrington) Pearson - wet rocks. Godfrey and Schofield (1979).

Frullania Raddi

nisquallensis Sullivant - branches and bark, decayed wood and humus on rocks. 99-175.

Gymnomitrion Corda

concinnatum (Lightf) Corda - rocks. Schofield 24279 (UBC).

obtusum Lindb. - acid rocks. 99-253.

pacificum Grolle - wet rocks. (Persson 1958; Schofield 1968).

Herbertus Gray

aduncus (Dicks.) Gray - bark and soil. Schofield 24788 (UBC).

sakuraii (Warnst.) S. Hatt. - bark and soil. 99-194.

Hygrobiella Spruce

laxifolia (Hook.) Spruce - peat bog. Schofield 25058 (UBC). (Schofield 1968).

Jungermannia L.

hyalina Lyell - wet soil or soil covered rocks. Persson s.n. (S). (Váña \& Hong 1999).

obovata Nees - shaded, decayed wood and wet soil near stream. 99-245.

pumila With. - wet rocks near stream. 99-266a.

Kurzia G. Martens

sylvatica (A. Evans) Grolle - decayed wood and soil. 99165.

Lepidozia (Dumort.) Dumort.

filamentosa (Lehm. \& Lindenb.) Lindenb. - shaded, decayed wood (Persson1958)

reptans (L. ) Dumort. - shaded, decayed wood. 99-255.

Lophozia (Dumort.) Dumort.

incisa (Schrad.) Dumort. - shaded, moist decayed wood. 99-285.

Iongiflora $($ Nees ) Schiffn. [ = ventricosa var. Iongiflora (Nees) Macoun;

= guttulata (Lindb. \& Arm.) Schiffn.] - decayed wood and soil. 99-255.

opacifolia Culm. ex Meyl. - wet soil. 00-402.

sudetica (Nees) Grolle - wet outcrop. 00-394.

ventricosa (Dicks.) Dumort. - decayed wood and soil. 99-218.

wenzelii (Nees) Steph. - humus on decayed wood. 00-475.

Marsupella Dumort.

alpina (Gottsehe ex Husn.) Bernet. - rocks. 99-253.

boeckii (Austin) Kaal. - rocks. 99-179 (Hong 1992).

emarginata (Ehrh.) Dumort. - moist soil near stream and wet rocks. 99-218.

var. aquatica (Lindenb.) Dumort. - submerged. 99-168. This variety is very abundant, covering wet rocks in the streamlets of the entire meadow, disdistinguished from var. emarginata by its rigid texture, black color, shallow- 
ly bilobed leaves with narrow sinus and bulging trigones. Many rhizoids are distinctly purplish.

Moerckia Gottsche

blyttii (Moerch) Brockm. - wet soil near stream. 00-479.

Mylia Gray

taylorii (Hook.) Gray - shaded, decayed wood and moist soil. 99-191.

Nardia Gray

compressa (Hook.) Gray - seep margins of stream. 99-198. geoscyphus (De Not.) Lindb. - moist soil and wet rocks near stream. 00-411.

japonica Steph. - soil. Schofield 25028 (UBC).

scalaris Gray - moist soil and wet rocks near stream. 99$266 b$.

Pellia Raddi

endiviifolia (Dicks.) Dumort. - wet rocks and soil near stream. 99-266a.

epiphylla (L.) Corda - moist soil near stream. 01-190.

neesiana (Gottsche) Limpr. - moist soil near stream. 99200.

Plagiochila (Dumort.) Dumort.

porelloides (Torrey ex Nees) Lindenb. - moist soil and decayed wood. 99-214.

Pleurocladula Grolle

albescens (Hook.) Grolle - moist soil near stream. 01-196. (Persson 1958).

Pleurozia Dumort.

purpurea Lindb. - peat bog. Schofield 25058 (UBC). (Schofield 1968)

Ptilidium Nees

californicum (Austin) - bark and decayed wood. 99-175.

Radula Dumort.

auriculata Steph. - shaded, wet cliffs and bark. Schofield 25060 (UBC). Schofield (1968).

obtusiloba subsp. polyclada (A. Evans) S. Hatt. - wet rocks, soil and humus on decayed wood. 00-464.

Riccardia Gray

latifrons (Lindb.) Lindb. - shaded, decayed wood and peat. 00-433.

palmata (Hedw.) Carruth. - shaded, decayed wood. 99-255.

Scapania (Dumort.) Dumort.

americana Müll. Frib. - wet soil near stream. 01-68.

bolanderi Austin - bark, decayed wood and soil. 99-170.

paludosa (Müll. Frib.) Müll. Frib. - wet rocks near stream. 01-104.

undulata (L.) Dumort. - shaded, decayed wood and wet soil near stream and waterfalls. 99-256. Many collections show distinct reddish-blackish color due to light exposure and are superficially similar to S. uliginosa.

var. oakesii (Austin) Müll. Frib. - wet rocks near stream. $01-104$.

Tritomaria Schiffn. ex Loeske quinquedentata (Huds.) H. Buch - shaded rocks. 99-214.

\section{Geographical Relationships}

The known hepatic flora of Takakia Lake area consists of 70 taxa; twelve different distributional elements (Table 1) are presented. The world distribution categories follow those given in Belland et al. (1992) and Hong (1999).

1. Cosmopolitan elements ( 2 taxa $3.0 \%$ ). The taxa of this group are not restricted to major vegetational biomes - arctic, boreal, temperate and tropical zones.
TABLE 1. The floristic affinities of the Hepaticae of Takakia Lake.

\begin{tabular}{lcr}
\hline \hline Elements & $\begin{array}{c}\text { Number of } \\
\text { hepatics }\end{array}$ & $(\%)$ \\
\hline 1. Cosmopolitan & 2 & $(3.0)$ \\
2. Circumboreal & 23 & $(32.2)$ \\
3. Boreal disjunct & 14 & $(19.6)$ \\
4. North American boreal endemic & 1 & $(1.5)$ \\
5. Circumtemperate & 3 & $(4.6)$ \\
6. Temperate disjunct & 6 & $(8.5)$ \\
7. North American temperate endemic & 1 & $(1.5)$ \\
8. Circum-montane & 3 & $(4.6)$ \\
9. Disjunct-montane & 2 & $(3.0)$ \\
10. Arctic and alpine & 8 & $(11.4)$ \\
11. Amphi-Pacific & 5 & $(7.1)$ \\
12. Western North American endemic & 2 & $(3.0)$ \\
\hline Total & 70 & $(100.0)$ \\
\hline \hline
\end{tabular}

Jungermannia hyalina and Riccardia palmata belong to this element.

2. Circumboreal elements (23 taxa, 32.2\%). Almost one-half of the hepatics around the lake belong to the boreal elements (51.8\%), and are predominantly (32.2\%) circumboreal. The latter are widespread throughout the Northern Hemisphere within the boreal biomes. Representative taxa are Anastrophyllum assimile, Barbilophozia hatcheri), B. lycopodioides, Blepharostoma trichophyllum, Calypogeia integristipula, C. neesiana, Cephalozia lunulifolia, C. macounii, Diplophyllum taxifolium, Gymnomitrion concinnatum, Jungermannia pumila, Lepidozia reptans, Lophozia incisa, L. Iongiflora, L. ventricosa, L. wenzelii, Marsupella emarginata and var. aquatica, Nardia compressa, N. geoscyphus, Plagioichila porelloides, Riccardia latifrons and Tritomaria quinquedentata.

3. Boreal elements (14 taxa, 19.6\%). The species of this group have major gaps in their world distribution. Representative taxa are Barbilophozia voerkei, Bazzania tricrenata, Cephalozia leucantha, Diplophyllum albicans, Gymnomitrion obtusum, Hygrobiella laxifolia, Moreckia blyttii, Mylia taylori, Nardia scalaris, Pellia endiviifolia, P. epiphylla, Pleurozia purpurea, Scapania undulate and var. oakesii.

4. North American boreal endemic elements (a taxon, $1.5 \%$ ). Only one taxon, Diplophyllum imbricatum, belongs to this element.

5. Cicumboreal element ( 3 taxa, $4.6 \%$ ). The taxa of this group; are widely distributed in the temperate forests of the Northern Hemisphere including Europe, Asia and eastern and western North America. Examples are Calypogeia azurea, Cephalozia bicuspidata, and Pellia neesiana.

6. Temperate disjunct elements ( 6 taxa, $8.5 \%$ ). The taxa of this group occur in the same region as the above group; however, they are absent from one or two of the above regions. Examples are Gymnomitrion pacificum, Herbertus aduncus, Kurzia sylvatica, Lepidozia fila- 
mentosa, Plagiochila semidecurrens, and Radula auriculata.

7. North American temperate endemic elements (a taxon, $1.5 \%$ ). The taxon is restricted to temperate forest of North America. Scapania americana belongs to this group.

8. Circum-montane elements ( 3 taxa, $4.6 \%$ ). The taxa in this element are Bazzania pearsonii, Marsupella alpina and M. boeckzii.

9. Disjunct-montane elements (2 taxa, 3.0\%). Only Jungermannia obovata and Scapania paludosa belong to this element.

10. Arctic-alpine elements ( 8 taxa, $11.4 \%$ ). The taxa restricted to arctic and alpine areas. Examples are Anthelia julacea, A. juratzkana, Barbilophozia kunzeana, Cephalozia ambigua, Eremontus myriocarpus, Lophozia opacifolia, L. sudetica and Pleurocladula albescens.

11. Amphi-Pacific elements (5 taxa, 7.1\%). The taxa of this group occur in the Northern Pacific coast of Asia (from Kamchatka to the northern tip of the Philippines, including southeastern area of China, Formosa, the southern part of Korea and Japan) and North America (from Alaska to California, including the southwestern part of Yukon, Idaho and western part of Montana). Examples are Diplophyllum plicatum, Herbertus sakuraii, Nardia japonica, Ptilidium californicum, and Scapania bolanderi (see Hong 1988).

12. Western North American endemic elements (2 taxa, $3.0 \%$ ). The taxa of this group are restricted to the western part of North America, including Frullania nisqualensis and Radual obtusiloba subsp. polyclada.

\section{Acknowledgments}

The author thanks E. McAllister, R. McDowell, D. Lund, A. Alt, Rv. J. Sikora, A. Graetzenberg, V. Matthews, and Sisters M. Benoit and K. Nealen for their assistance. I am also grateful to W. Schofield for suggestions and helpful comments on the original manuscript.

\section{Literature Cited}

Belland, R. J., W. Schofield, and T. Henderson. 1992. Bryophytes of Mingan Archipelago National Park Reserve,
Quebec: a boreal flora with arctic and alpine components. Canadian Journal of Botany 12: 2207-2222.

Calder, J. A., and R. L. Taylor. 1968. Flora of the Queen Charlotte Islands. Part 1. Canada Department of Agriculture. Ottawa.

Godfrey, J. D., and W. B. Schofield. 1979. New and interesting Hepaticae from British Columbia, Canada, and northwestern Washington State, U.S.A. II. The Bryologist 82(2): 162-170.

Grolle, R., and D. G. Long. 2000. An annotated check-list of the Hepaticae and Anthocerotae of Europe and Macronesia. Journal of Bryology. 33: 215-217.

Hattori, S. 1963. Takakia in North Borneo. Journal of Japanese Botany 38: 215-217.

Hattori, S., and H. Inoue. 1958. Preliminary report on Takakia lepidozioides. Journal of the Hattori Botanical Laboratory 19: 133-137.

Hong, W. S. 1988. The distribution of western North American Hepaticae Endemic taxa and with a North Pacific Arc distribution. The Bryologist 90: 344-361.

Hong, W. S. 1992. The genus Marsupella in western North America. Lindbergia 8: 166-176.

Hong, W. S. 1993. The genus Gymnomitrion in North America west of the hundredth meridian. Lindbergia 9: 169-177.

Hong, W. S. 1999. Hepatics of the Vladmir Ecological Reserve, Queen Charlotte Islands, Canada. Haussknechtia Beiheft 9: 183-192.

Miller, H. A. 1968. Herberta Notes. Journal of the Hattori Botanical Laboratory. 31: 247-250.

Mizutani, M. 1974. Koke no Soseiki [Genesis of Mosses]. Shida to Koke [Ferns and Mosses]. 8(1): 6.

Murray, B. M. 1988. Systematics of the Andreaeopsida (Bryophyta): Two orders with links to Takakia. Beiheft Nova Hedwigia 90: 289-336.

Persson, H. 1958. The genus Takakia found in North America. The Bryologist 61: 354-361 .

Schofield, W. B. 1968. Bryophytes of British Columbia. II. Hepaticae of particular interest. Journal of the Hattori Botanical Laboratory 31: 265-282.

Smith, D., and P. G. Davidson. 1990. Sporophyte of Takakia discovered. The Bryological Times 57/58: 1-4.

Stotler, R., and B. Crandall-Stotler. 1977. A checklist of the liverworts and hornworts of North America. The Bryologist 80: 405-428.

Váña, J., and W. S. Hong. 1999. The genus Jungermannia in western North America. Lindbergia 24: 133-144.

Received 4 October 2001

Accepted 28 March 2007 